\title{
The effect of wall and floor colouring on temperature and draught feeling of primary school children
}

\author{
Philomena M. Bluyssen ${ }^{1, *}$, Dadi Zhang $^{1}$, Arend-Jan Krooneman ${ }^{1}$ and Arno Freeke ${ }^{1}$ \\ ${ }^{1}$ Faculty of Architecture and the Built environment, Delft University of Technology, Delft, The Netherlands
}

\begin{abstract}
To investigate whether different colours of the indoor surfaces could have an effect on thermal comfort of children, 335 primary school children were invited to take part in a series of tests conducted in the thermal test chamber of the SenseLab. A three-way factorial randomized design was used to test the effect of three different colours of walls (white, red and blue) and floor (grey, green and blue) on the temperature and draught feeling in a winter situation (sunlight coming in: heat) and a summer situation (opening window: draught). A statistical relevant relationship between feeling of draught and feeling of temperature was found. Except for a significant difference in temperature feeling for different floor colours when the wall colour was red in the winter situation, no relevant effects (or interaction effects) were found for differences in wall or floor colours on the temperature or draught feeling.
\end{abstract}

\section{Introduction}

In a recent field study of 54 classrooms of 21 primary schools in the Netherlands, was found that among the 1145 children studied (average 10 years old) $42 \%$ was bothered by sunlight when shining, $35 \%$ didn't like the temperature in the classroom (too cold or too warm), $34 \%$ experienced temperature changes and only $7 \%$ was bothered by draught [1]. The significant relationship between presence of solar shade devices on the outside and thermal comfort responses (feeling too warm/feeling too cold) at child level, indicated that classrooms with external solar shades have fewer children feeling thermally dissatisfied. Also, the relationship between thermal comfort and ventilation type was significant at child level. It was concluded that the thermal environment seemed very much related to the indoor (air) and outdoor (light) environment of the classrooms, being an interplay between sunlight coming in, the presence of heating, cooling and air conditioning systems, solar screens (hampering ventilation or not), operable windows, and the actions of the children and the teachers (opening doors, windows, solar shades etc.). Additionally, from the inspection of the classrooms was found that the colours of the floors had the most variation, while walls and ceilings were generally white. From studies with adults it is known that different colours can directly affect an individual's impression of environmental parameters [2]. For example, for temperature, light blue is usually experienced as cooler and red/orange as warmer. Also, preferences for colour might differ per child [3] and the colour/light combinations of indoor environmental surfaces seem to have an effect on perceptual performance of school children (e.g. colour of walls [4]) and their behaviour and mood [5]. But whether the colours of the indoor surfaces could have an effect on thermal comfort (temperature and draught), has not yet been investigated with children.
To investigate preferences and needs, but also responses to single components and interactions of different environmental conditions more in depth, 335 children from the previous studied schools, were invited to take part in a series of tests in a semi-laboratory environment: the SenseLab. The SenseLab comprises of four test chambers (one for each IEQ factor: air, light, acoustics and thermal aspects) and the Experience room (a room for integral perception) [6]. In the thermal test chamber, the effect of different colours of walls and floor on the thermal comfort and draught feeling in a winter situation (sunlight coming in: heat) and a summer situation (opening window: draught) was tested.

\section{Methodology}

\subsection{Study design}

This study was part of a series of tests performed with children from the previous studied schools, in the SenseLab [6]. A three-way factorial randomized design was used to test the effect of different colours of walls and floor on the thermal comfort and draught feeling in a winter situation (sunlight coming in: heat) and a summer situation (opening window: draught). The different classroom situations (colours of walls: red, blue or white; and floor: green, grey or blue), were created with Virtual Reality in combination with a construction lamp (simulating the heat of the sun) and a fan (simulating the draught of fresh air). Each combination was tested by a group of children from primary schools, comprising on average of 14 children per group. In Table 1 the 18 different combinations tested are presented. 
Table 1. Randomized testing scheme.

\begin{tabular}{|c|c|c|c|c|c|c|c|c|c|}
\hline Test & Date & $\begin{array}{c}\begin{array}{c}\text { No. of } \\
\text { children } \\
\mathbf{N}\end{array} \\
\end{array}$ & Walls & Season & Floor & $\begin{array}{l}\text { Girls } \\
\text { n }(\%)\end{array}$ & $\begin{array}{c}\text { Having a } \\
\text { cold } \\
\text { n }(\%)\end{array}$ & $\begin{array}{c}\text { Mean age } \\
(\mathrm{yr} .)\end{array}$ & $\begin{array}{c}\text { Feeling bad at } \\
\text { this moment } \\
\text { n }(\%)\end{array}$ \\
\hline 1 & $15 / 02 / 18$ & 14 & red & winter & grey & $6(43)$ & $6(43)$ & 11.43 & $0(0)$ \\
\hline 2 & $20 / 02 / 18$ & 10 & white & winter & green & $5(50)$ & $1(13)$ & 9.40 & $0(0)$ \\
\hline 3 & & 15 & white & winter & blue & $10(67)$ & $5(36)$ & 9.33 & $2(13)$ \\
\hline 4 & $22 / 02 / 18$ & 12 & white & summer & green & $2(17)$ & $4(33)$ & 10.00 & 0.0 \\
\hline 5 & & 12 & red & winter & blue & $5(42)$ & $6(50)$ & 10.08 & $4(33)$ \\
\hline 6 & & 12 & blue & winter & grey & $9(75)$ & $8(73)$ & 10.33 & $1(8)$ \\
\hline 7 & $08 / 03 / 18$ & $19 * *$ & red & winter & green & $9(47)$ & $4(21)$ & 11.47 & $0(0)$ \\
\hline $8^{*}$ & & $11 * *$ & white & summer & blue & $5(46)$ & $5(46)$ & 10.55 & $0(0)$ \\
\hline 9 & & 14 & blue & summer & green & $6(43)$ & $5(36)$ & 11.71 & $1(7)$ \\
\hline 10 & $15 / 03 / 18$ & 12 & blue & winter & blue & $8(67)$ & $5(42)$ & 11.08 & $0(0)$ \\
\hline $11^{*}$ & & 14 & red & summer & blue & $6(43)$ & $2(14)$ & 11.29 & $0(0)$ \\
\hline 12 & $20 / 03 / 18$ & 14 & blue & summer & blue & $6(43)$ & $7(50)$ & 10.43 & $0(0)$ \\
\hline 13 & & 14 & white & winter & grey & $11(79)$ & $11(79)$ & 10.29 & $2(14)$ \\
\hline 14 & $27 / 03 / 18$ & 15 & blue & summer & grey & $5(33)$ & 7 (47) & 11.00 & $0(0)$ \\
\hline 15 & & 15 & red & summer & grey & $12(80)$ & $4(27)$ & 11.47 & $0(0)$ \\
\hline 16 & $03 / 04 / 18$ & 16 & red & summer & green & $6(38)$ & $10(63)$ & 9.56 & $2(13)$ \\
\hline 17 & & 16 & blue & winter & green & $7(44)$ & $4(25)$ & 9.38 & $0(0)$ \\
\hline $18^{*}$ & & 14 & white & summer & grey & $7(50)$ & $4(29)$ & 9.29 & $1(7)$ \\
\hline mean & & 13.8 & & & & $6.9(50)$ & $5.4(40)$ & 10.50 & $0.7(5)$ \\
\hline
\end{tabular}

*: these summer situation tests were performed immediately after a winter situation test.

**: test 7 was performed by 19 children, due to a delay in the change of the exposure situation; and test 8 was therefore only evaluated by 11 children.

\subsection{Facilities}

During the SenseLab studies the thermal comfort test chamber of the SenseLab was used as a virtual reality experiment to test the thermal comfort of a group of participating school children. In this experiment two primary school children took place behind a school desk per test run, sitting next to each other and wearing VR headsets (see Figure 1). The VR experience took place in a virtual classroom (see Figure 2), that was made in Unreal Engine 4, using two HTC Vive VR headsets.

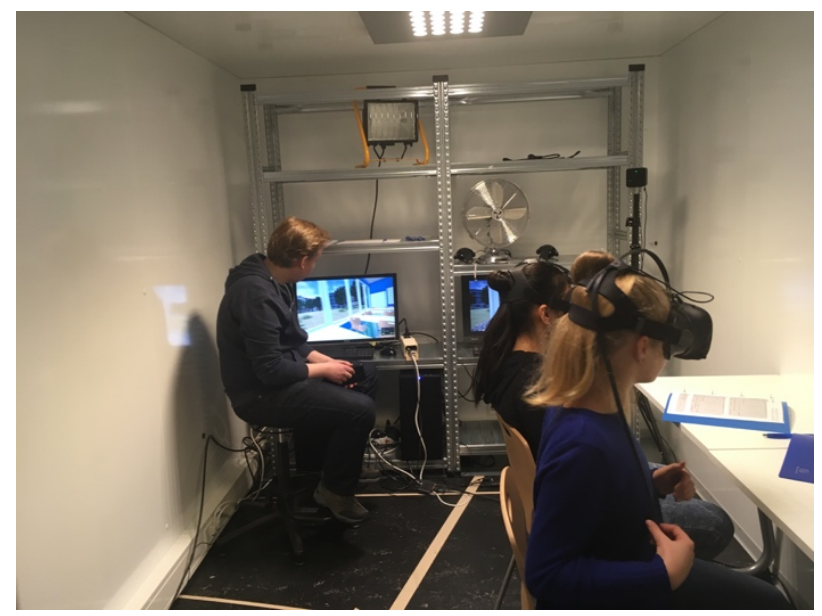

Figure 1. The Thermal test chamber set-up.
In order to make a realistic experience the actual school desk and chair were recreated in 3D and placed in the virtual model. By aligning the physical desk with the VR desk, the participants could actually touch and feel the furniture while wearing their VR headset, giving them an increased sense of immersion.

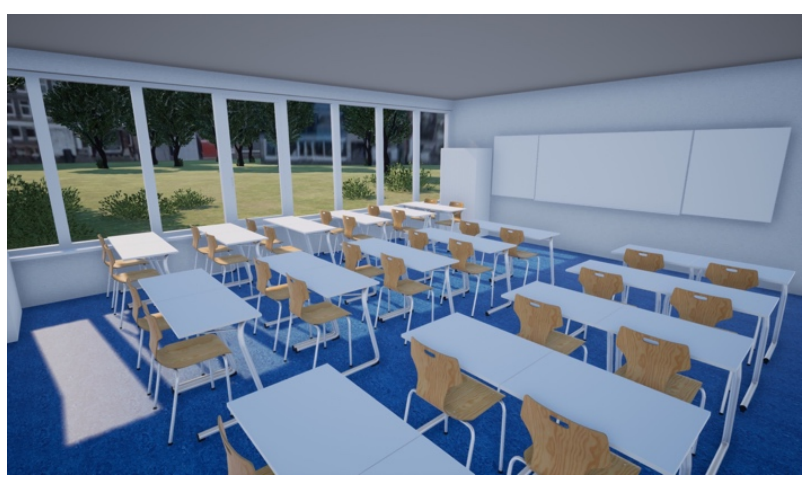

Figure 2. Virtual classroom with blue flooring and white walls.

To simulate sunlight shining into the classroom in VR, a $1000 \mathrm{~W}$ construction light was used in the actual room. This light turned on and radiated heat onto the children. When the blinds closed, this construction light also turned off, so the temperature feeling changed instantly. For the simulation of wind during the summer situation, an electrical fan was placed in the same position in the real room as the classroom window in VR. When this window opened, the fan started up and blew cool air at the children. This sensation of the warmth of sunlight 
and the coolness of wind resulted in an increased experience of the senses and believability of the virtual classroom.

\subsection{Procedure}

When the children arrived in the SenseLab, they completed a one-page questionnaire with personal information and were divided into groups (randomly) of maximum 16 children per group. Per day, a maximum of three groups could perform the tests. One group started in the Experience room, one group was divided over the four test chambers (maximum of 4 children per test chamber) and the third group visited the Science Centre (the location in which the SenseLab is located). After approximately 35 minutes the groups changed: group 1 went to the test chambers, group 2 visited the Science Centre and group 3 went into the Experience room.

In each of the test chambers (light, sound, air and thermal), different tests were performed. Every 7-8 minutes, after the tests were performed, the children changed to another test chamber.

The tests performed in the thermal test chamber are presented here. In this thermal test chamber each group of children was exposed to a different test combination. The tests were performed with 1-2 children at the time, a two-minute test run each, and afterwards they completed a one-page questionnaire about their comfort in the virtual classroom (see Figure 3 ). The children who were done with the test, waited to go to the next test chamber for other tests.
Based on the combination to be tested, the classroom had a different combination of colours for the floor and walls. Beside this colour variation there was also a winter or summer simulation. In winter the sun shined directly through the window onto the children until the window blinds lowered and darkened the room. In the summer situation the window next to the participant opened and the wind blew inside cooling the room.

\subsection{Data management and analysis}

All data from the questionnaires were manually typed in and stored in IBM SPSS Statistics 24.0. A second person systematically checked the input of the questionnaire data. Descriptive statistics such as percentages, range or arithmetic mean with standard deviation were used to summarize the data. The 18 combinations were split into two groups: the winter and the summer exposed, and then analysed.

To study possible relationships between the different assessments of temperature and draught and the different colours of floor and walls, the assessment made by the children were given a number from 1 to 5 ( 1 to 4 for did you feel draught). ANOVA (one-way and two-way) and Pearson, assuming a continuous scale and normal distribution, were used to analyse relationships [7]. Additionally, simple main effects analysis of floor colour within each level of combinations of the other effects, based on linearly independent pairwise comparisons among the estimated marginal means, was performed for both the winter and summer situations.

\section{Questionnaire Thermal Comfort}

In a minute, you will get a VR device on your head. You will then sit next a window in a classroom.

After your VR-experience, which will take approximately 1.5 minutes, could you answer the following questions?

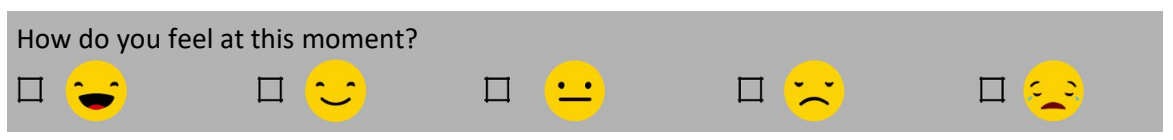

How did the temperature feel?

$\square$ Cold $\square$ Slightly cold $\square$ Normal $\quad \square$ Slightly warm $\square$ Warm

Did you feel draught?

$\square$ A lot $\square$ Yes $\square$ A little $\square$ No
How did the draught feel? (if 'No' to previous question, you do not need to answer)

Figure 3. Questionnaire for thermal comfort test. 


\subsection{Ethical aspects}

After recruitment of the schools, the parents received an information letter and a consent letter from the school management, which usually happened two weeks before the visit. On the day of the visit, the research team received the consent forms usually from the teachers accompanying the children. For the children without permission to join the experiments, the school management generally decided not to have them join the visit.

The Ethics committee of the TU Delft gave approval for the study.

\section{Results}

\subsection{Participants}

In total 335 children from 7 primary schools participated to the SenseLab experiments that were held from February 13 to April 5 at 10 different days. For the tests performed in the Thermal test chamber, 18 combinations, excluding the first and the last day of testing, and excluding children who did not complete their form, resulted in responses of a total of 249 children with an average age of 10.5 years (SD of 1.1 years) and comprising of 50\% girls (see Table 1). $40 \%$ of them claimed having a cold and $5 \%$ felt bad at the moment of filling in the questionnaire (just after the VR experience).

\subsection{Thermal conditions}

Although the air supply temperature was set at $21{ }^{\circ} \mathrm{C}$, and supplied continuously with $250 \mathrm{~m}^{3} / \mathrm{h}$, it was monitored during the tests that the air temperature in the thermal test chamber increased up to $23^{\circ} \mathrm{C}$ with the presence of people only (summer situation) and up to 25 ${ }^{\circ} \mathrm{C}$ in the situation that the construction light was turned on and off (winter). Exhaust of the air in the thermal test chamber is based on overflow by an exhaust grille next to the door and by opening and closing the door. In between the tests with the different groups, the door was left open to reduce the temperature inside. For the summer tests combinations $(8,11$ and 18 , see Table 1) that were performed after a winter test combination, the air temperature monitored was between 23 and $25^{\circ} \mathrm{C}$.

\subsection{Descriptives}

Because the exposure to the winter and summer combination caused an approximately two degrees Celsius difference in the air temperature - the children of the different groups tested were clearly exposed to different thermal conditions - it was decided to separate the results of the two seasons (see Tables 2 and 3).

For the question "How did the temperature feel?", the first two possible answers were combined and the last two answers were combined, resulting in three answers: cold, normal and warm. The same was done for the question "How did the draught feel?", resulting in the three answers: good, normal and bad. For the latter

Table 2. Results of winter test combinations.

\begin{tabular}{|l|c|c|c|c|c|c|c|c|}
\hline $\begin{array}{l}\text { Combination } \\
\text { Winter }\end{array}$ & $\mathrm{N}$ & \multicolumn{3}{|c|}{$\begin{array}{c}\text { How did the temperature feel? } \\
\mathrm{n}(\%)\end{array}$} & $\begin{array}{c}\text { Did you feel } \\
\text { draught? n }(\%)\end{array}$ & \multicolumn{3}{|c|}{$\begin{array}{c}\text { How did the draught feel?* } \\
\text { n }(\%)\end{array}$} \\
\hline Wall; floor & & Cold & Normal & Warm & Yes & Good & Normal & Bad \\
\hline red; grey & 14 & $0(0)$ & $5(35.7)$ & $9(64.3)$ & $8(57.1)$ & $8(57.1)$ & $0(0)$ & $0(0)$ \\
\hline red; blue & 12 & $0(0)$ & $2(16.7)$ & $10(83.3)$ & $5(41.7)$ & $3(25)$ & $2(16.7)$ & $0(0)$ \\
\hline red; green & 19 & $0(0)$ & $9(47.4)$ & $10(52.6)$ & $11(57.9)$ & $10(52.6)$ & $1(5.3)$ & $0(0)$ \\
\hline white; grey & 14 & $0(0)$ & $7(50)$ & $7(50)$ & $10(71.4)$ & $7(50)$ & $3(21.4)$ & $0(0)$ \\
\hline white; blue & 15 & $1(6.7)$ & $9(60)$ & $5(33.3)$ & $10(66.7)$ & $6(40)$ & $4(26.7)$ & $0(0)$ \\
\hline white; green & 10 & $0(0)$ & $8(80)$ & $2(20)$ & $5(50)$ & $5(50)$ & $0(0)$ & $0(0)$ \\
\hline blue; grey & 12 & $1(8.3)$ & $3(25)$ & $8(66.7)$ & $6(50)$ & $3(25)$ & $2(16.7)$ & $1(8.3)$ \\
\hline blue; blue & 12 & $1(8.3)$ & $5(41.7)$ & $6(50)$ & $4(33.3)$ & $4(33.3)$ & $0(0)$ & $0(0)$ \\
\hline blue; green & 16 & $1(6.3)$ & $8(50)$ & $7(43.8)$ & $5(31.3)$ & $4(25)$ & $1(6.3)$ & $0(0)$ \\
\hline Mean & 13.9 & $0.4(3)$ & $6(45)$ & $7(52)$ & $6.5(51)$ & $5(40)$ & $1.4(11)$ & $0.1(0)$ \\
\hline
\end{tabular}

*: without those No to previous question.

Table 3. Results of summer test combinations.

\begin{tabular}{|l|c|c|c|c|c|c|c|c|}
\hline $\begin{array}{l}\text { Combination } \\
\text { Summer }\end{array}$ & N & \multicolumn{3}{|c|}{$\begin{array}{c}\text { How did the temperature feel? } \\
\text { n }(\%)\end{array}$} & $\begin{array}{c}\text { Did you feel } \\
\text { draught? n }(\%)\end{array}$ & \multicolumn{3}{|c|}{$\begin{array}{c}\text { How did the draught feel?* } \\
\text { n }(\%)\end{array}$} \\
\hline Wall; floor & & Cold & Normal & Warm & Yes & Good & Normal & Bad \\
\hline red; grey & 15 & $2(13.3)$ & $7(46.7)$ & $6(40)$ & $15(100)$ & $14(93.3)$ & $1(6.7)$ & $0(0)$ \\
\hline red; blue** & 14 & $3(21.4)$ & $10(71.4)$ & $1(7.1)$ & $14(100)$ & $12(85.7)$ & $2(14.3)$ & $0(0)$ \\
\hline red; green & 16 & $4(25)$ & $8(50)$ & $4(25)$ & $15(93.8)$ & $14(87.5)$ & $1(6.3)$ & $0(0)$ \\
\hline white; grey** & 14 & $3(21.4)$ & $6(42.9)$ & $5(35.7)$ & $12(85.7)$ & $12(85.7)$ & $0(0)$ & $0(0)$ \\
\hline white; blue** & 11 & $7(63.6)$ & $3(27.3)$ & $1(9.1)$ & $11(100)$ & $11(100)$ & $0(0)$ & $0(0)$ \\
\hline white; green & 12 & $1(8.3)$ & $11(91.7)$ & $0(0)$ & $12(100)$ & $10(83.3)$ & $2(16.7)$ & $0(0)$ \\
\hline blue; grey & 15 & $1(6.7)$ & $12(80)$ & $2(13.3)$ & $15(100)$ & $13(86.7)$ & $2(13.3)$ & $0(0)$ \\
\hline blue; blue & 14 & $3(21.4)$ & $7(50)$ & $4(28.6)$ & $14(100)$ & $11(78.6)$ & $2(14.3)$ & $1(7.1)$ \\
\hline blue; green & 14 & $4(28.6)$ & $8(57.1)$ & $2(14.3)$ & $14(100)$ & $12(85.7)$ & $2(14.3)$ & $0(0)$ \\
\hline Mean & 13.8 & $3.1(22)$ & $8.2(57)$ & $3(21)$ & $13.7(96.3)$ & $12.3(86)$ & $1.3(9.5)$ & $0.1(0.8)$ \\
\hline
\end{tabular}

*: without those No to previous question; $* *$ : test performed after a winter condition. 
question, only the answers of the children who felt draught were used.

For the feeling of temperature, the results of the winter tests showed that on average $52 \%$ children felt warm, $45 \%$ felt normal and 3\% felt cold, while in the summer tests $21 \%$ felt warm, $57 \%$ felt normal and $22 \%$ felt cold.

From the results of the summer tests can be seen that almost all children felt the draught (96\%), while in the winter situation $51 \%$ felt draught while the fan was not turned on. Only two children, one in the winter and one in the summer test situation, did not like the draught they felt.

\subsection{Relationships}

The results of the different types of analysis are presented in Tables 4 and 5 and Figures 4 and 5.

The comparison between the answers to the questions 'How did the temperature feel?' and "How did the draught feel?", showed a significant relationship for the winter situation (Table 4). The colder the children felt, the better they liked the draught.

For the comparison of children's votes among different environmental settings no statistical relevant relationships were found (Table 5).

A two-way ANOVA was conducted to examine the effect of wall colour and floor colour on children's temperature and draught feeling. For both the summer and the winter situations tested, no statistically significant interactions between the effects of wall colour and floor colour on children's temperature or draught feeling were found.

For the winter situation (exposed to heat of construction lamp), simple main effects analysis showed that children experienced the temperature significantly different when exposed to different floor colours for the wall colour red $(\mathrm{p}=0.037)$. They felt much warmer in the situation with the blue floor. But there were no significant differences in temperature feeling between different floor colours when the wall colour was white $(\mathrm{p}=0.397)$ or blue $(\mathrm{p}=0.386)$ (Figure 4).

For the summer condition (exposed to draught caused by a fan), simple main effects analysis showed that the children felt no significant difference in draught for different floor colours with a white $(\mathrm{p}=0.559)$, red $(\mathrm{p}=0.400)$ or blue wall colour $(\mathrm{p}=0.083)$ (Figure 5).
Table 4. Relationships between children's temperature and draught feeling votes.

\begin{tabular}{|r|c|c|}
\hline & Summer & Winter \\
\hline $\mathrm{r}^{*}$ & 0.028 & 0.409 \\
\hline $\mathrm{P}^{* *}$ & 0.764 & $\mathbf{0 . 0 0 1}$ \\
\hline
\end{tabular}

$* \mathrm{r}=$ Pearson correlation coefficient; $* * \mathrm{P}=\mathrm{P}$-value. $\mathrm{P}$-values in bold refer to significant relationships at 5\% level.

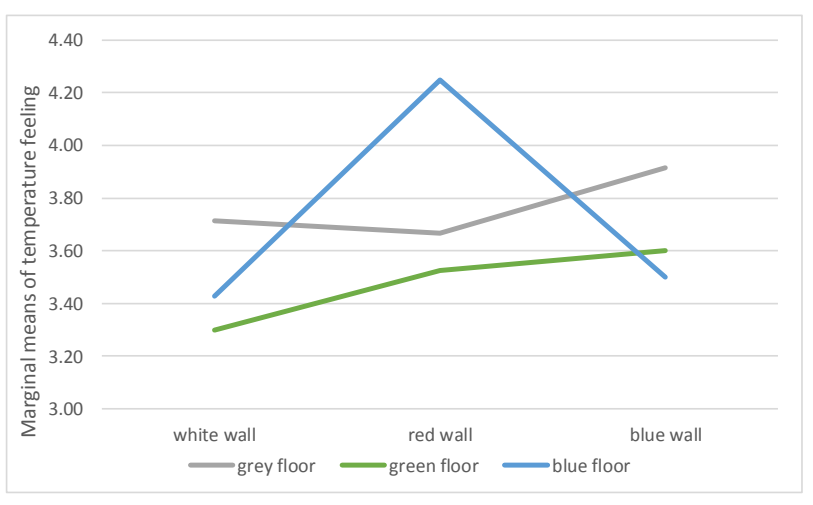

Figure 4. Estimated marginal means of temperature feeling in winter situation for different wall colours and floor colours.

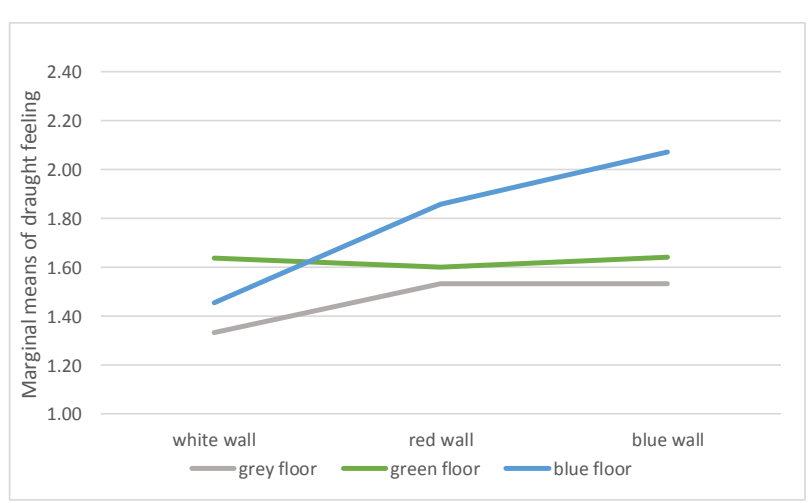

Figure 5. Estimated marginal means of draught feeling in summer situation for different wall colours and floor colours.

Table 5. Comparison of children's votes among different environmental settings.

\begin{tabular}{|c|c|c|c|c|c|c|c|}
\hline & & \multicolumn{3}{|c|}{ Temperature vote (mean) } & \multicolumn{3}{|c|}{ Draught vote (mean) } \\
\hline & & All & Summer & Winter & All & Summer & Winter \\
\hline \multirow{3}{*}{ Wall colour } & White & 3.19 & 2.86 & 3.50 & 1.64 & 1.47 & 1.91 \\
\hline & Red & 3.44 & 3.11 & 3.76 & 1.70 & 1.66 & 1.76 \\
\hline & Blue & 3.33 & 3.02 & 3.67 & 1.83 & 1.74 & 2.07 \\
\hline \multicolumn{2}{|c|}{ P-value (ANOVA) } & 0.142 & 0.307 & 0.319 & 0.361 & 0.211 & 0.456 \\
\hline \multirow{3}{*}{ Floor colour } & grey & 3.47 & 3.20 & 3.76 & 1.64 & 1.48 & 1.92 \\
\hline & green & 3.23 & 2.95 & 3.50 & 1.70 & 1.63 & 1.86 \\
\hline & blue & 3.27 & 2.85 & 3.71 & 1.84 & 1.82 & 1.88 \\
\hline \multicolumn{2}{|c|}{ P-value (ANOVA) } & 0.130 & 0.065 & 0.281 & 0.289 & 0.075 & 0.966 \\
\hline
\end{tabular}




\section{Discussion}

\subsection{General}

Except for a significant difference in temperature feeling for different floor colours when the wall colour was red in the winter situation, no relevant effects were found of differences in wall or floor colours on the temperature or draught feeling. Several reasons can be put forward for this outcome. First, the randomized procedure for the different settings, and the short time of the test as well as the time between the different tests with the individual children, influenced the air temperature within the thermal test chamber. Second, for each combination of wall and floor colour for either a winter or a summer conditions, tests were performed with a certain group of children only once. Therefore, no individual comparison could be made for the exposure to different colours of walls and floor. For the only individual comparison that could be made, that is between the feeling of the experienced temperature and draught, a statistical relevant relationship was found for the winter situation.

\subsection{Winter situation and temperature}

From the temperature votes can be seen that even though the air temperature in the test chamber was $25^{\circ} \mathrm{C}, 48 \%$ of the children still felt normal or even cold during the winter situations tested. There are several possible reasons for this. First, the occupancy time of the children in the test chamber was no longer than 4 minutes (of which only 2 minutes in the VR classroom), which is short compared to actual occupancies in their own classroom. Second, the children evaluated the conditions after they had done the test; during the test they were distracted by the VR-programme, which they all were intrigued by very much. Third, as was found in a study of 4866 children at primary and high schools by Kim and de Dear [8], the range of school children's thermal sensations regarded as acceptable is wider than that of adults. And fourth, children might just differ in their preferences for temperature, as was found by Zhang et al. [9] in a field study of primary school children in The Netherlands, which makes it difficult to use group results.

\subsection{Summer situation and draught}

During the summer situation, a fan was turned on to simulate draught caused by opening of a window in the VR-classroom. Almost all children felt the draught and all except one, liked the draught. The influence of the different colours of walls and floor didn't show any relationship with the assessments of draught or temperature.

As in the field study [1] very few children were bothered by the draught. With respect to the feeling of temperature, $43 \%$ felt the temperature either too warm or too cold, which was higher than in the field study $(35 \%)$. This might be explained by a slightly higher indoor air temperature during the tests as compared to the field studies (mean of $23.1^{\circ} \mathrm{C}$ in the field) [1] or by the fact that the group of children as individuals just responded slightly different [9].

\section{Conclusions}

The study presented was part of a larger study in which primary school children performed several tests in four test chambers and a workshop in the experience room. This study was a first attempt to study the effect of different wall and floor colours on the thermal perception of children with the use of different technologies.

The VR-technique made it possible to change the environment in an instant, without having to actually change the environment physically, while the construction light and the fan provided the means to change the indoor climate. It certainly gives new opportunities for research in the future.

In the future a test focused on individual assessment by comparing different situations for each child seems necessary to pursue in order to be able to study the effect of different colours on thermal sensations. Additionally, the timing and planning of the tests need to be optimised.

\section{References}

1. P.M. Bluyssen, D. Zhang, S. Kurvers, M. Overtoom, M. Ortiz-Sanchez, Self-reported health and comfort of school children in 54 classrooms of 21 Dutch school buildings, Building and Environment 138: 106-123 (2018).

2. F.H. Mahnke, Color, environment \& human response, New York: John Wiley \& Sons (1996).

3. J.G.P. Park, Correlations between color attributes and children's color preferences. Color research and application 39(5):452-462 (2014).

4. K. Yildirim, K. Cagatay, N. Ayalp, Effect of wall colour on the perception of classrooms, Indoor and Built Environment 2015; 24(5):607-616.

5. H. Wohlfart, Color and light effects on students' achievement, behaviour and physiology, Edmonton, Alberta, Canada: Faculty of Extension, University of Alberta; Report (1986).

6. P.M. Bluyssen, F. van Zeist, S. Kurvers, M. Tenpierik, S. Pont, B. Wolters, L. van Hulst, D. Meertins, The creation of SenseLab: A laboratory for testing and experiencing single and combinations of indoor environmental conditions, Intelligent Buildings International 10:1, 5-18 (2018).

7. B.G. Tabachnick and L.S. Fidell, Experimental designs using ANOVA, International Student Edition (Brooks/Cole 2006).

8. J. Kim and R. de Dear, Thermal comfort expectations and adaptive behavioural characteristics of primary and secondary school students, Building and Environment 127: 13-22 (2018).

9. D. Zhang, M. Ortiz, P.M. Bluyssen, Clustering of Dutch school children based on their preferences and needs of the IEQ in classrooms, Building and Environment 147: 258-266 (2019). 